IZA DP No. 5194

The Lasting Impact of Mothers' Fetal Malnutrition on Their Offspring:

Evidence from the China Great Leap Forward Famine

Seonghoon Kim

Quheng Deng

Belton M. Fleisher

Shi Li

September 2010 


\title{
The Lasting Impact of Mothers' Fetal Malnutrition on Their Offspring: Evidence from the China Great Leap Forward Famine
}

\author{
Seonghoon Kim \\ Ohio State University \\ Quheng Deng \\ Chinese Academy of Social Sciences \\ Belton M. Fleisher \\ Ohio State University, \\ CUFE Beijing and IZA \\ Shi Li \\ Beijing Normal University \\ and IZA
}
Discussion Paper No. 5194
September 2010

\author{
IZA \\ P.O. Box 7240 \\ 53072 Bonn \\ Germany \\ Phone: +49-228-3894-0 \\ Fax: +49-228-3894-180 \\ E-mail: iza@iza.org
}

\begin{abstract}
Any opinions expressed here are those of the author(s) and not those of IZA. Research published in this series may include views on policy, but the institute itself takes no institutional policy positions.

The Institute for the Study of Labor (IZA) in Bonn is a local and virtual international research center and a place of communication between science, politics and business. IZA is an independent nonprofit organization supported by Deutsche Post Foundation. The center is associated with the University of Bonn and offers a stimulating research environment through its international network, workshops and conferences, data service, project support, research visits and doctoral program. IZA engages in (i) original and internationally competitive research in all fields of labor economics, (ii) development of policy concepts, and (iii) dissemination of research results and concepts to the interested public.
\end{abstract}

IZA Discussion Papers often represent preliminary work and are circulated to encourage discussion. Citation of such a paper should account for its provisional character. A revised version may be available directly from the author. 
IZA Discussion Paper No. 5194

September 2010

\section{ABSTRACT \\ The Lasting Impact of Mothers' Fetal Malnutrition on Their Offspring: Evidence from the China Great Leap Forward Famine*}

We find that second-generation effects of in utero and early childhood malnutrition on the school participation of the offspring of mothers who experienced the China Great Leap Forward Famine. The direct impact on entrance to senior high school is also negative, but smaller in magnitude than that on entrance to junior high school. Given that entering senior high school is contingent on completion of junior high school, the direct impact on entrance to senior high school obviously understates the total impact on the second generation's accumulation of human capital. Our estimation results are generally robust to IV estimation.

JEL Classification: $\quad$ I12, J16, P36

Keywords: malnutrition, health, schooling, Barker hypothesis, China Famine

Corresponding author:

Belton M. Fleisher

Department of Economics

Ohio State University

410 Arps Hall

1945 N. High Street

Columbus, $\mathrm{OH} 43210$

USA

E-mail: fleisher@econ.ohio-state.edu

\footnotetext{
* We thank Avraham Ebenstein, Simon Chang, Jikun Huang, Audrey Light, Trevon Logan, Nancy Qian, Scott Rozelle and Richard Steckel, and participants of seminars at the Center for Chinese Agricultural Policy of the Chinese Academy of Sciences and Ohio State University for valuable comments. We are grateful to the China Health and Nutrition Survey, funded by NIH (R01-HD30880, DK056350, and R01-HD38700), and the Carolina Population Center and the Chinese CDC for providing data. Members of the Friday Working Group, Will McGuire, Kerry Tan, and Kent Zhao patiently listened to many presentations of the material and made valuable comments throughout.
} 


\section{Introduction}

We investigate whether mothers' in utero and infant malnutrition adversely impact the human capital of their offspring (the second generation). While much has been learned about the long-term effects of malnutrition on adult outcomes of the first generation (Barker, 1992 and much subsequent research), much less is known about second-generation outcomes. Because the cost of acquiring additional units of human capital is a decreasing function of the stock (including health capital) beginning in the prenatal period (Behrman et al., 2004), any influence of first generation malnutrition on fetal development of the second generation is likely to reduce the payoff to public and private investments in schooling, training, and other forms of human capital investment. It follows that the existence of second-generation effects on human capital development implies a multiplier for policies that support the nutrition of pregnant women and infants. The China Great Leap Forward famine (China Famine), generally recognized as the worst in world history as measured by mortality and length (Li and Yang, 2005), provides a natural experiment from which information on second-generation effects of malnutrition can be obtained.

In 1958, Mao Zedong initiated an ambitious but reckless economic and social experiment, the Great Leap Forward (GLF) movement, which was intended to transform rural China into industrial China and thus to catch up with Russia in a quarter century and the United States in half a century (Li and Yang, 2005). The China Famine was a direct consequence of the GLF movement interacting with other poorly designed government policies that included excessive grain procurement which in turn was encouraged by local incentives to exaggerate output and the government's ignorance of local conditions as well as exports of grain for foreign exchange to procure imports of required physical capital (Lin and Yang, 2000). These negative influences interacted with severe weather conditions to produce a decline in China's grain output of 15\% in 1959 and an additional 16\% in 1960 (Li and Yang, 2005). The sudden collapse of grain supply along with minimal will to redistribute grain among rural areas resulted in around 16-30 million excess deaths between 1959 and 1961 (Li and Yang, 2005; Luo et al. 2006; Chen and Zhou, 2007). The famine was widespread all over China but had large regional variation (figure 5). Moreover, urban bias on the part of the Communist regime meant that urban residents suffered much less, because they had preferential access to food supplies (Lin and Yang, 2000).

After realizing the severity of the famine, the Communist party changed course in 
January 1962. Agricultural output rebounded and grain imports increased. Equally or more important, grain procurement was reduced, and death rates dropped quickly (Figure 1). Birth rates rebounded, although in a more complex fashion. After increasing sharply in 1962 and 1963, birth rates started to drop in 1964; this fluctuation suggests the influence of selective childbearing decisions of parents (Shi, 2008).

We suggest two potential paths through which first-generation malnutrition shocks may impact the second generation: First, the child of a famine-born mother may suffer due to famineinduced defects in the mother's ova ${ }^{1}$ (direct channel), so that a woman's, pre-birth and early-life malnutrition may adversely affect her reproductive capacity. We also investigate whether those children who are exposed to malnutrition in their first- or second years of life appear to suffer from developmental deficiencies that impact the achievements of their offspring. Second, women born around the time of famine tend to acquire lower social and economic status (SES) than those born outside the famine period and this in turn may lead to lower human capital development among their children than the children would otherwise acquire (indirect channel). Deficiencies in scheduled brain and body development in a woman's prenatal and early infancy periods of life are likely to have cumulative effects on the cost of her future investments and, hence, her lifetime accumulation of human capital. Thus, acquired schooling, earning capacity, income, available marriage partners, and other factors affecting a woman’s child-rearing potential are likely to be negatively impacted by in utero and early infancy exposure to famine (Victoria et al. 2008).

Researchers have documented a number of long-term adverse effects of malnutrition in utero or in infancy on first-generation outcomes in adults born during several major famines, ${ }^{2}$ These include physical impacts such as heart diseases and stunted height, mental problems such as schizophrenia, and economic outcomes, such as house size, household income, and related variables (Almond et al., 2008a, 2008b; Barker, 1992; Behrman et al., 2004; Chen and Zhou,

\footnotetext{
${ }^{1}$ Epidemiological studies suggest that "adverse in utero experiences may permanently affect maternal growth and development, altering [the mother's] metabolism in such a way as to provide an adverse environment for her fetus (Drake and Walker, 2004)." During the in utero and early post-birth stages of life, the body directs available nutrition first toward survival and then for other physical needs such as scheduled brain and body development or maintaining daily functions (Steckel, 1995, Behrman et al., 2004).

${ }^{2}$ Famines in the recent history that have been the subject of such research include the Irish Potato famine of the $19^{\text {th }}$ century, the Dutch famine of the second World War, the Ethiopia famine (1984-1985, 1998-2000), the Somali famine (1991-1993).
} 
2007; Fung, 2009; Luo et al., 2006; Meng and Qian, 2009; Mu and Zhang, 2008; Roseboom et al., 2001; Shi, 2008; Yamauchi, 2008). However, there has been little research on secondgeneration impacts of famine ${ }^{3}$. Almond, et al. (2008) do find an increase in the ratio of female children among second-generation births, from which they infer support for the Trivers-Willard hypothesis (Trivers and Willard, 1973); Fung and Ha (2009) find negative outcomes on heightfor-age, in the offspring age 0-18 of women born during the China Famine. They also find negative effects on weight-for-age and years of schooling, but only for girls.

[summary of our findings and policy implications]

The rest of this paper is organized as follows. The next section discusses methodological issues and presents our analytical framework. Section 3 reviews literature related to the impact of the famine on first-generation human capital and labor market outcomes; section 4 describes the data and sample selection; section 5 reports the estimation results, and section 6 concludes, with policy implications and suggestions for further research.

\section{Methodology}

Our major hypothesis is that the net impact of a mother's in-utero and early infancy malnutrition on the development of her offspring is negative. Our approach is to use provincial weighted excess death rates as a measure of mothers' exposure to in utero and early childhood malnutrition in probit regressions analysis of the probability that their children (the second generation) enter junior or senior high school. ${ }^{4}$. We use a two-way fixed effects approach and specify the probits to include only the weighted excess death rate and also to include household characteristics of the mother's family that should capture indirect effects of in utero or early childhood malnutrition on the mothers' socio-economic achievements in adult life.

Famine Impact on Fecundity and Survival. Necessarily, estimates of second-generation effects of mothers' in utero or early infancy malnutrition are conditional on conception and survival of both first generation mothers and of their offspring. It is likely that during the China Famine, both behavioral and health factors affected fecundity and decisions to marry and to have children (the first generation). In addition, surviving women conceived under adverse conditions

\footnotetext{
${ }^{3}$ Studies of birth outcomes and physical growth include those of Fung (2009); Gorgens, Meng, and Vaithiannathan, (2007); and Currie and Moretti, (2005).

${ }^{4}$ By "high school" we refer to what is literally designated "middle school" in Chinese.
} 
may also bear traits that have affected their fecundity as well as their desire to conceive and bear children (the second generation), as well as the survival probabilities of their (second-generation) children (Chen and Zhou, 2007). During the famine period, birth rates dropped significantly while death rates surged. Peng (1987) argued that about 25 million potential births were lost or delayed due to the China Famine because of adverse health and economic impacts on the famineexposed child-bearing generation. We believe that our inability to observe individual characteristics such as income, schooling, or related variables of the first-generation mothers' parents is likely to bias our empirical results against rejecting the null of no famine impact on the second generation. This belief is based on our conjecture that those who were born during the China Famine are more likely to have had parents living in an area that was not as severely affected as other regions in the same province ${ }^{5}$, and/or parents of higher socioeconomic status, both of which factors are likely to have contributed positively the innate traits and life outcomes of (first-generation) children born during the famine period. ${ }^{6}$. It is not obvious a priori whether the combined impact of first-and second-generation conception and survival impacts would work in favor of observing "better" or "worse” traits in the observed (surviving) second generation. Plausible scenarios can be constructed supporting both positive and negative biases. In the absence of experimental data, we recognize that estimates of second-generation effects are conditional on unobserved and (in human samples) probably unobservable intervening conditions. In the remainder of this paper, we recognize that all estimation and interpretation is conditional on the presence of possible conception and survival biases affecting both the firstand second generations.

Econometric Model. Our basic model for identifying the impact of famine on the outcomes listed above is represented by the following equation:

$$
Y_{i j k l}=f\left(\mathrm{WEDR}_{j k l}, X_{i}, Z_{l}, F_{l}, \varepsilon_{i j k l}\right)
$$

where

- $\quad \mathrm{Y}_{i j k l}$ is a second-generation individual $i$ 's variable of interest, such as high-school entrance.;

\footnotetext{
${ }^{5}$ We do not have data on these sub-provincial impacts of the famine.

${ }^{6}$ Shi (2008) studied fertility selection around the China Famine period. He found a positive selection among famineborn cohorts, i.e., holding other things constant, famine-born cohorts have better innate traits than others.
} 
- $\mathrm{WEDR}_{j k l}$ is a measure of famine intensity (malnutrition) - the weighted excess death rate by year, month and province of birth for person i's mother who was born in year j,province $l$ and month $k$;

- $X_{i}$ is a vector of household characteristics variables such as house type, size of house, and number of children,

- $F_{l}$ is a vector of dummy variables to capture time-varying and province-varying fixed effects and variables to represent recalled weather conditions during every year covered in our data. The weather data are those used by Li and Yang (2005) ${ }^{7}$.

Econometric Challenges The variable WEDR is the best approximation available to us for the availability of nutrition to our sample of mothers. It is calculated as the difference between the annual provincial death rate from which is subtracted the mean provincial death rate between 1956-1958 following Chen and Zhou (2007). In Figure 1, we see that death rates are quite stable before 1958, and they abruptly surge during the China Famine of 1959-1961. An underlying assumption is that the famine's effects on caloric intake are proportional to excess mortality. Following Almond et al. (2008a), the death rate for each observation is weighted according to the number of months a second-generation's mother was in utero during year $\mathrm{j}$ and in year j-1 for individuals born in the first 8 months of year j (based on a 9-month gestation period).

Measurement Error and Rural-Urban Migration. The variable WEDR obviously measures the nutrition available to individual mothers with error, because it is an average for a province and year, and available nutrition is determined at the household level; thus local and family factors influencing available food are not reflected at the individual level. This error-invariables (EIV) problem leads to attenuation bias, against rejecting the null hypothesis of no effect. A specific measurement problem, also potentially leading to a bias in the estimated impact of famine on both first- and second-generation outcomes is related to classifying families according to whether they live in rural or urban areas. Non-migrant urban families were by definition living in urban areas during the China Famine, and, as is well-known, the impact of the famine on available nutrition was far less than for rural families. Indeed, one reason for the severity of famine in rural areas was procurement of food for transfer to urban population (Li and

\footnotetext{
${ }^{7}$ We are grateful to Dennis Tao Yang and Wei Li for generously providing data for these variables.
} 
Yang, 2005).

Regarding rural-urban migrants, some mothers that change their residence from rural to urban locations may do so in order to obtain better schooling for their offspring, and this motivation may be stronger for children about to enter senior high school. ${ }^{8}$ However, one reason for mothers to return to their rural homes has been to guide children when they are enrolled in school. (Connelly et al, 2010a and 2010b) An unobserved omitted “motivation” variable could bias our estimation results if it is correlated with WEDR. However, we have no reason to believe that the unobserved motivation is correlated with WEDR and we therefore have no reason to suspect a bias due to omission of this variable from our estimation. Moreover, all of our estimation results include dummy variables for mother's birth province and mother's birth year. We believe that these fixed effects are likely to control for any intertemporal and interprovincial variation in omitted variables associated with motivation to achieve higher schooling levels for offspring.

Omitted Variables. Perhaps a more serious problem than simple measurement error is that WEDR may be correlated with unobserved local government actions that influence mothers' and children's health and other forms of human capital. The behavioral determinants of famine are well documented in both the theoretical and empirical literature. (Sen, 1981a, 1981b; Lin and Yang1998, 2000; Li and Yang, 2005) Variation in nutritional insufficiency is likely to be due not only to climatic and policy shocks exogenous to local government decisions, but also to the ways in which governments at various levels behaved, including deciding how much grain output to report. ${ }^{9}$ It is plausible that provincial and local government decisions that partially explain local famine severity are correlated with policies toward public health, education, and other publicly provided services that affected first- or second-generation human-capital formation. We conjecture that omission of these variables from OLS regression would bias our estimates against rejecting the null of no famine impact on the second generation.

We deal with potential omitted variable bias by instrumenting WEDR with five dummy

\footnotetext{
${ }^{8}$ Mothers who bring their children to an urban area would be required to send them to (generally inferior) migrant schools or pay higher fees for standard schools if they do not possess the appropriate hukou.

${ }^{9}$ We thank Scott Rozelle for emphasizing this point. One of the causes of local food insufficiency was overreporting of production, which led to increased grain procurement. (Li and Yang, 2005 and other references document the importance of excessive procurement.)
} 
variables representing time- and province-varying weather conditions ${ }^{10}$ as used by Li and Yang (2005). These variables are derived from a retrospective survey conducted by Li and Yang as described in an Appendix to their paper. ${ }^{11}$ All of the variables pertain to a period well before the birth dates of our second-generation sample, are very unlikely to be correlated with residuals of the second-generation human-capital and labor market outcome regressions. Moreover, the firststage estimates shown in table 6 provide strong evidence that the instruments can "explain” the GLF famine.

\section{Related Literature}

Much of the literature relevant to this study is conceptually based on the Barker hypothesis, also known as the fetal origin hypothesis (Barker, 1992). The Barker hypothesis states that a variety of human characteristics are determined in utero. A small, but growing, body of literature treats the effects of fetal malnutrition on economic and social outcomes. Researchers generally rely on historic famines such as the Dutch Famine of the second World War, the China Famine, and others as natural experiments to study the impacts of in utero and early infancy malnutrition.

First-generation effects. A number of researchers have found that famine-related malnutrition experience in utero or infancy has long-term negative effects on economic, social and health outcomes among those who directly suffered in utero and/or early childhood malnutrition--the first generation. Almond et al. (2008a) use data from the 1\% sample of 2000 China Population Census to show that among individuals born around the time of the China Famine, adult literacy, house size, working ability, and the probability of being married are all less than those characteristics of the general population who were born outside the famine period. Shi (2008) also finds similar results on adult outcomes using the same 2000 China Population Census data,and provides some suggestive evidence on selective fertility that only healthier women conceive children during the famine and weaker women began conceiving right after the famine . Using data from the China Health and Nutrition Survey (hereafter, CHNS), Chen and Zhou (2007) and Meng and Qian (2009) provide evidence that those who experienced the China Famine in utero or in infancy have lower height, labor supply, earnings, and other characteristics

\footnotetext{
${ }^{10}$ Meng and Qian (2009), using a different data set also used county-level grain productivity (per capita area suitable for cultivating rice and wheat, and per capita area of rice and wheat sown) to instrument for famine intensity.

${ }^{11}$ We are grateful to the authors for providing these data.
} 
indicating a negative impact on their human capital. With the same data, Fung (2009) finds that women who experienced the famine in early life are more likely to have a higher body mass index (BMI) and to be obese. The literature investigating people born around the Dutch famine yields similar results: Roseboom et al. (2001) and Bleker et al. (2005) show that fetal malnutrition negatively affected physical health outcomes in later lives.

Prenatal exposure to famine has been shown also to have negative impacts on mental health. For example, Susser et al. (1992) show that those who experienced the Dutch Famine in utero exhibited a 2-fold increase in the risk of schizophrenia. A negative impact on adult antisocial personality disorders is also reported among those exposed to the Dutch Famine in utero (Neugebauer, Hoek, and Susser, 1999). Clair et al. (2005) find similar results among the China Famine cohort.

Second-generation effects. Although they do not directly use a famine as a quasi-natural experiment a few studies examine whether there are second-generation effects of a mother's early-life malnutrition (or low birth weight as a proxy for early-life nutritional status). Secondgeneration outcomes examined include, birth weight, height, cardiovascular diseases, test scores, and other markers (Emanuel et al., 2004; Drake and Walker, 2004; Currie and Moretti, 2007). Drake and Walker (2004) argue that adverse fetal environments such as malnutrition may harm maternal development which changes maternal metabolism and through this affects her fetus. Figure 2 illustrates the propagation mechanism of intrauterine growth shock from a mother to her child.

As mentioned in the introduction, there are two studies of second-generation effects of early-life maternal malnutrition during the China famine. Almond et al. (2008a) report an increase in the ratio of female births in the second generation based on a 1\% sample of 2000 China Population Census_ - quite surprising at first sight when one considers China's well-known son preference. The authors interpret this preponderance of female births as consistent with the Trivers-Willard hypothesis, which states that "evolution would favor parental ability to vary the sex ratio of offspring according to condition: parents in poor condition would biologically favor daughters and parents in good condition would favor sons” (Trivers and Willard, 1973); Fung and Ha (2009) study the second generation effects of early-life maternal malnutrition and find adverse second-generation effects of individuals whose mothers are born during the famine, such as lower height-for-age, lower weight-for-age, and fewer years of schooling. However, Fung and 
Ha's investigation is based on samples obtained by pooling three CHNS waves that include the same individuals interviewed in three different years; these repeated observations are treated as though they were independently observed in the same year, and the reliability of their regression results is therefore questionable. Another problem with Fung and Hua (2009) is that they use the 1989, 1991, and 1993 CHNS waves in which the offspring of famine-born cohorts are very young. Despite their restriction of the sample to those who are 6-18 years old, using years of schooling to test for education outcomes is problematic, because schooling through lower middle school (junior high school) is mandatory while senior high school education is not. Our study focuses on discretionary schooling choices.

\section{Data and Sample Selection}

Our Data are taken from the China Census of Population 2000, and the sample covers 31 provinces with 1.18 million observations. Tibet and Haizhan are dropped because the required mortality data is not available. ${ }^{12} \mathrm{~A}$ unique advantage of the 2000 census is the availability of birth provinces, with makes it possible to relate offsprings' data to the province-specific famine exposure of their mothers. Our sample includes all children with mothers born in the period 1954 through 1996. Further restrictions limit children's ages as appropriate for the schooling level studied. For example, in exploring the effect of mothers' malnutrition on the probability of their offspring entering junior high school, we include only children age 13-15.

We divide our sample into eight subgroups, with the most fundamental division being between urban and rural residents, because the China Famine was primarily a rural phenomenon. The rural and urban samples are further divided into male and female offspring, and children age 13-15 (for junior high school entrance) and 16-18 (for senior high school entrance). Sample statistics are presented in tables $1 \mathrm{a}$ (for offspring age 13-15) and $1 \mathrm{~b}$ (for offspring age 16-8). The first column in each table shows the sample mean weighted excess death rate (WEDR) per 1,000 persons for each year covered by our data, 1954 through 1966 . We show only the values of mean WEDR for the sample of rural males age 16-18, because this is the largest of the eight subgroups in our data, and because the values of this variable differ by very little across the

\footnotetext{
${ }^{12}$ Chongqing is treated as part of Sichuan. It was upgraded to metropolitan status in 1997. Hainan could be treated as part of Gangdong, but it was upgraded to a province in 1988, much earlier. We choose to delete Hainan to avoid errors that would occur over a much longer stretch of the time period covered in our data than would be case for Chongqing and Sichuan.
} 
various subsamples, which differ by age group, gender, and rural-urban location. The mean WEDR over all years is -1.24 and reaches a high of 8.46 in the year $1960 .^{13}$

The other sample statistics shown in tables $1 \mathrm{a}$ and $1 \mathrm{~b}$ are the proportion of mothers in each subgroup who were born in each year, and the proportion of offspring who entered the specified schooling level in each year. The sample distribution across mothers' birth years is related to the age of the offspring subgroups, with the frequency of birth years of the younger group of offspring tending to peak in the mid-1960s, while the frequency of birth years of the older group of offspring tend to peak in the years prior to 1960. There is a visible decline in the frequency of birth years during the famine years 1959-1961 among mothers with rural residence in the year 2000, but any tendency of a decline in the frequency of births in the famine years is not obvious among urban-residing mothers.

The proportion of offspring entering the two schooling levels_-junior high school and senior high school ${ }^{14}$--is of course larger for the lower schooling level, and it is larger for the urban offspring than for rural offspring, with the urban-rural gap much larger for senior high school than for junior high school. The mean proportion of rural males entering junior high school is slightly larger than that for rural females, but the gender gap is negligible among urban offspring. Among rural offspring, a higher proportion of males than females entered senior high school, but among urban offspring, the gap is reversed, with $74.2 \%$ on average of females entering high school compared to only $70.7 \%$ of males. Within all the eight subgroups, there is a downward trend across mothers' birth year in the proportion of offspring entering each level of schooling. We attribute this decline, not to a falling level of schooling attainment, but rather to declining average age of the offspring as mothers’ birth year moves from 1954 through 1966. Our inclusion of dummy variables for mothers' birth year in all our estimations should control for this age-related phenomenon.

\section{Estimation Results}

Our ordinary and two-stage (IV) probit estimation results are reported in tables 2a

\footnotetext{
${ }^{13}$ While mean WEDR is by definition 0 when the units of observation are provinces and years, it can deviate from 0 due to sample variation in birth dates and number of offspring born in each year and province.

${ }^{14}$ We use the term high school instead of the literal translation of the Chinese, "middle school".
} 
through 2 d. First-stage estimations results for the two-stage probits are shown in table $3 .{ }^{15}$ We show estimated probit coefficients and their $z$-values, and for the WEDR variable, we also show the marginal probability of entering the specified school level calculated at the mean value of the WEDR variable, in braces. We also multiply the marginal probability coefficient by one standard deviation of WEDR in the specified subgroup and show this calculation in braces as the fourth item in all of the WEDR cells. For example, for rural females' junior high-school entrance, the number -0.016 in the fourth row, first column of table 2a indicates that a one standard deviation in WEDR is associated with a reduced probability of entering junior high school of 1.6 percentage points. Another metric for the size of this impact is to multiply the marginal probability by the mean value of WEDR in the year 1960, the peak of the China Famine induced death rates. This calculation yields a product of approximately 2.7 percentage points. Both of these measures may be compared to the average proportion of rural females who entered junior high school during the sample period, approximately 70 percent in each year.

The estimated probit coefficients are uniformly negative and generally statistically significant in all ordinary probit regressions for rural offspring entering junior- or senior high school. The estimated probit coefficients for junior high-school are generally robust to the inclusion of variables that represent families' economic status-housing type, housing area, and number of offspring; the signs of all of these control variables are as expected. However, the inclusion of the housing and offspring variables leads to a decline in statistical significance for high-school entrance.

As discussed above, if the possibility of omitted-variable bias arising from failure to consider province-specific political factors that affected both famine severity and other aspects of human-capital development such as provision of health care and schooling must be considered. To investigate the possibility that our ordinary probit estimates are biased by this omittedvariable problem, we have conducted two-step IV-probit estimation in which the WEDR is treated as an endogenous variable. The instruments are dummy variables based on interviews conducted by Wei Li and Dennis Yang and reported in their paper (Li and Yang, 2005) cited above. Li and Yang also use several other variables related to the political "atmosphere" in the

\footnotetext{
${ }^{15}$.The instrumental variables used are individually significant and are jointly significant to explain famine intensity and are orthogonal to residuals in the second stage regression according to over-identifying test statistics. See detailed explanation of the instrumental variables in Li and Yang (2005)
} 
provinces during and preceding the famine period, but they are not in general time-varying and therefore must be captured by the province dummies used in our first-step regressions. The firststep regression results don't vary much across our four subsamples, and we report only results for the rural subgroups in table 3. The explanatory power of the weather dummies is high, and the estimated coefficients are all positive (in relationship to weather reported as "very good") with their magnitudes for "bad" and "very bad" being substantially larger than the magnitudes for "good" and "average".

The second-step probit estimation results are generally robust to alternative specifications of included regressors, and the Wald-test statistic indicates that it is difficult to reject the null that the weather dummies are valid exogenous variables. To save space, we report the 2-step probit results only for the simplest specification of the school-entrance equations. For junior-high school entrance, the estimated probit coefficients of WEDR are much larger in absolute value than their oridinary-probit counterparts, and statistically significant by conventional standards. However, for senior high school entrance, the second-step estimates are quite insignificant. We conclude that the null of negligible impact of mother's in utero malnutrition on the likelihood of her offspring entering senior high school conditional on entering junior high school cannot be rejected.

We also report probit results in which the WEDR during mothers' first and second years of life is used alone as an independent variable or jointly with the WEDR while mothers were in utero. For female offspring, we estimate a negative impact of malnutrition during both their firstand second years of life on the probability of entering junior high school. For males, we estimate a negative, although statistically insignificant by ordinary standards, impact of first-year mother's malnutrition on the probability of entering junior high school. But curiously, we obtain a positive estimate of WEDR during male offsprings' second life year. For both female and male offspring, when WEDR when mother was in utero is interacted with WEDR during the mothers' second life year, the impact of WEDR when mother was in utero is quite robust. When WEDR during mothers' first or second life year is added to the senior high-school probits for rural offspring, the estimated coefficients are all negative, but not statistically significant

The estimated coefficient of WEDR is never never negative for urban offspring, and zstatistics range from a low of 0.74 (for urban males entering junior high school) to a high of 1.90 
(for urban females entering junior high school). ${ }^{16}$ As discussed above and documented in the literature, the China Famine was primarily a rural phenomenon, and the province-wide death rates we observe do not represent the famine impact on the urban population.

As discussed in a preceding section, we believe that the possible biases inherent in using a province-wide measure of the impact of malnutrition for the urban subsample biases our estimates against rejecting the null hypothesis of no malnutrition effect compared to the alternative hypothesis that there are negative second-generation impacts of famine-induced malnutrition on second-generation offspring school attainment. Unfortunately, the 2000 Census data do not provide information on rural-urban migration within provinces, but we do have information on whether province of current residence is different than province of birth. Approximately 2.5 percent of the urban sample and 0.9 percent of the rural sample's mothers were born in different provinces than their residence in 2000. We can safely assume that the vast majority of the small proportion of the rural sample who have migrated between provinces are rural-to-rural migrants, and mothers’ birth areas are therefore correctly identified. Moreover, if even half of the urban interprovincial migrants are rural-urban migrants, they would constitute somewhat more than 1 percent of the urban sample. To test the robustness of our probit estimates, we have added a dummy variable equal to 1 if mother's birth province is not the province of her residence in the year 2000 and its interaction with WEDR. The estimated coefficient of WEDR for both urban males and females entering junior high school is somewhat smaller and lower in statistical significant when the interprovincial migration variables are included. It is quite interesting to note that for females, the interaction of mother's interprovincial migration with WEDR is quite large and statistically significant, suggesting that mothers from high death-rate provinces who migrated out of those provinces to urban areas were highly motivated to send their daughters to junior high school, but further speculation is beyond the scope of this study. The results are similar in sign for urban males, but the coefficient of the interaction term between WEDR and mother's migration status is insignificant. The inclusion of the migration variables in the rural probits produces no substantial change in the estimated regression coefficients of WEDR during mothers' in utero period.

\footnotetext{
${ }^{16}$ We do not report 2-step probit estimation results for the urban samples. We find no evidence that the positive estimated coefficients of WEDR are attributable some kind of omitted-variable or endogeneity bias.
} 


\section{Concluding Remarks}

. Social scientists have found that the effects of early life malnutrition are durable, widespread, and last through adult life of those who are born of mothers who suffered malnutrition in utero or in early infancy (the first generation). We investigate whether similar adverse outcomes are found in the second generation: children born of the first-generation mothers. The China Famine, a tragic event in the world history, provides an opportunity to examine the link between malnutrition and social, economic, and the health outcomes of those who experience malnutrition in early life and of their progeny. We find that such secondgeneration effects do appear in lower probability of entering junior high school, and the magnitude of this effect is similar for both male and female offspring. The direct impact on entrance to senior high school is also negative, but smaller in magnitude than that on entrance to junior high school. Given that entering senior high school is contingent on completion of junior high school, the direct impact on entrance to senior high school obviously understates the total impact on the second generation's accumulation of human capital. Our estimation results are generally robust to IV estimation.

These results support the existence of an important multiplier of policies that support the nutrition of pregnant women and infants in any country where nutritional deficiencies remain. Indeed, China has recently taken steps to improve the nutritional status of children. The National Program of Action for Child Development in China aims to reduce the number of malnourished children under age 5 by a 25\% in 2010. According to the 2009 United Nations Millennium Development Goals Report, one-quarter of children in the developing regions are underweight and more than one-third of child deaths worldwide are associated with under-nutrition. If individual nations and international agencies do not take into account these second-generation effects of early-life malnutrition, they are likely to underestimate the long-term benefits of their pro-nutrition policy interventions. Even the outcomes we have identified to not capture the likely full and, long-term effects that last into the second generation. To measure these effects it would be necessary to separate the impacts of prenatal and perinatal malutrion and to follow the second-generation impacts into adulthood, middle- and old ages of the second generation. Impacts on the development of chronic physical and mental illnesses in the second generation remain to be identified. 


\section{$\underline{\text { References }}$}

Ashton, B., Kenneth, H., Piazza, A., and Zeitz, R. 1984. "Famine in China, 1958-1961.” Population and Development Review 10(4): 613-645.

Almond, Douglas, Lena Edlund, Hongbin Li, and Junsen Zhang, 2008a. "Long-Term Effects of The 1959-1961 China Famine: Mainland China and Hong Kong.” NBER Working Paper No. 13384

Almond, D. and Mazumder, B., 2008b. “The Effects of Maternal Fasting During Ramadan on Birth and Adult Outcomes.” NBER Working Paper No. 14428

Behrman J.R., Harold Alderman and John Hoddinott. 2004. "Hunger and Malnutrition, Copenhagen consensus challenges and opportunities.” In Global Crises, Global Solutions, ed. Bjorn Lomborg. Cambridge (UK): Cambridge University Press.

Cameron, A. Colin, and Trivedi, Pravin K. 2009. Microeconometrics Using Stata. College Station, Texas: Stata Press.

Chen, Y., L. and Zhou, A. 2007. “The Long-term Health and Economic Consequences of the 1959-1961 Famine in China.” Journal of Health Economics 26(4)

Clair, D., M. Xu, P. Wang, Y. Yu, Y. Fang, F. Zhange, X. Zheng, N. Gu, G. Feng, P. Sham, and L. He. 2005. "Rates of Adult Schizophrenia Following Prenatal Exposure to the Chinese Famine of 1959-1961.” JAMA 294(5): 557-562.

Connelly, Rachel, Roberts, Kenneth, Zheng, Zhenzhen, 2010a. The Role of Children in the Migration Decisions of Rural Chinese Women. Working Paper. Waterville, Maine: Department of Economics Bowdoin College.

Connelly, Rachel, Roberts, Kenneth, Zheng, Zhenzhen, 2010b. The Settlement of Rural Migrants in Urban China-Some of China’s Migrants Are Not “Floating” Anymore. Working Paper. Waterville, Maine: Department of Economics Bowdoin College

Currie, Janet, Moretti, Enrico. 2007. “Biology as Destiny? Short and Long-Run Determinants of Intergenerational Transmission of Birth Weight.” Journal of Labor Economics 25(2)

Drake, A. J. and Walker, B. R. 2004. “The Intergenerational Effects of Fetal Programming: Nongenomic Mechanisms for the Inheritance of Low Birth Weight and Cardiovascular Risk.” Journal of Endocrinology 180:1-16

Emanuel, Irvin, Kimpo, Christy, and Moceri Victoria. 2004. “The Association of Maternal Growth and Socio-economic Measures with Birth Weight in Four Ethnic Groups.” 
International Journal of Epidemiology 33:1236-1242

Fung, Winnie. 2009. "Early Childhood Malnutrition and Adult Obesity: Evidence from the 1959961 China Famine.” Ph.D. diss., Havard University

Fung, Winnie and Ha, Wei. 2009. "Intergenerational Effects of the 1959-61 China Famine.” In Risk, Shocks and Human Development: On the Brink. eds. Fuentes-Nieva and Seck. Palgrave-Macmillan: London.

Gørgens, Tue, Xin Meng, and Rhema Vaithianathan. 2007. "Stunting and Selection Effects of Famine: A Case Study of the Great Chinese Famine.” IZA Discussion Paper No. 2543

Lin, Justin W. and Yang, Dennis T. (1998). On the Causes of China's Great Leap Forward and the China Famine. China Economic Review 9, 125-140.

Lin, Justin W., and Yang, Dennis T. 2000. "Food Availability, Entitlements and the Chinese Famine of 1959-6.” The Economic Journal 110(460):136-158

Li, Wei, and Yang, Dennis T. 2005. "The Great Leap Forward: Anatomy of a Central Planning Disaster.”, Journal of Political Economy 113(4)

Liu A., Zhao L., Yu D., and Yu, W. 2008. "Study on malnutrition status and changing trend of children under 5 years old in China.” Working Paper, Institute for Nutrition and Food Safety, Chinese Center for Disease Control and Prevention.

Lumey, L. H. and Stein, A. D. 1997. "In Utero Exposure to Famine and Subsequent Fertility: The Dutch Famine Birth Cohort Study.” American Journal of Public Health 87(12):19621966

Lumey, L. H. and Stein, A. D. 2000. “The Relationship between Maternal and Offspring Birth Weights After Maternal Prenatal Famine Exposure: the Dutch Famine Birth Cohort Study.” Human Biology. 72(4):641-54

Luo, Z., Mu, R., and Zhang, X. 2006. “Gender Difference in the Long-Term Impact of Famine.” Review of Agricultural Economics 28(3):296-304.

Meng Xin and Nancy Qian, 2009. The Long Term Consequences of Famine on Survivors: Evidence from a Unique Natural Experiment using China's Great Famine, NBER Working paper No. 14917

Mu, Ren, and Zhang, X., 2008. "Famine and Overweight in China.” IFPRI Discussion Paper 00760

Peng, Xizhe. 1987. “Demographic consequences of the Great Leap Forward in China's 
provinces.” Population and Development Review, 13(4): 639-70.

Roseboom, Tessa J., Meulen, Jan H.P., Ravelli, Anita C.J., Osmond, Clive,Barker, David J.P., and Bleker, Otto P. 2001. "Effects of Prenatal Exposure to the Dutch Famine on Adult Disease in Later Life: An Overview.” Twins Research 4(5):293-298.

Sen, Amartya, 1981a. Poverty and Famines: An Essay on Entitledments and Deprivation. Oxford: Clarendon Press.

Sen, Amartya,1981b. Igcredients of Famine Analysis: Availability and Entitlements. Quarterly Journal of Economics 95, 433-464.

Shi, Xinzheng. 2008. “Famine, Fertility, and Fortune in China” Ph.D. diss., University of Michigan

Shonkoff, J. P., and Phillips, D. 2000. From Neurons to Neighborhoods: The Science of Early Child Development. National Academies Press, Washington DC

Steckel, Richard, H. 1995. "Stature and the Standard of Living." Journal of Economic Literature 33(4):1903-1940

Strauss, John, and Thomas, D. 1998. “Health, Nutrition, and Economic Development.” Journal of Economic Literature 36(2):766-817

Susser E, Lin, S. P. 1992. "Schizophrenia After Prenatal Exposure to the Dutch Hunger Winter of 1944-1945.” Arch Gen Psychiatry 49:983-988.

Trivers, Robert, and Willard, Rob E. 1973. "Natural Selection and the Ability to Vary the Sex Ratio of Offspring.” Science 179

United Nations, 2009. The Millennium Development Goals Report 2009. The United Nations Department of Economic and Social Affairs

Victoria, C.G., Adair, L., Fall, C., Hallal, P. C., Martorell, R., Richter, L. and Sachdev, H. S. 2008. “Maternal and Child Undernutrition: Consequences for Adult Health and Human Capital.” The Lancet 17:23-40

Wooldridge, Jeffrey M. 2002. Econometric Analysis of Cross Section and Panel Data, Cambridge, MA: MIT Press.

Yamauchi, Futoshi. 2008. "Early Childhood Nutrition, Schooling and Sibling Inequality in a Dynamic Context: Evidence from South Africa” Economic Development and Cultural Change 56(3)

Yang, Dennis Tao, and Cai Fang. 2003. How Far Across the River?: Chinese Policy Reform at 
the Millennium, Stanford University Press 
Table 1a Sample Statistics

\begin{tabular}{|c|c|c|c|c|c|c|c|c|c|}
\hline \multicolumn{10}{|c|}{ Offspring Characteristics Age 13-15 in 2000} \\
\hline \multirow{3}{*}{$\begin{array}{l}\text { Mother's } \\
\text { Birth Year }\end{array}$} & \multicolumn{5}{|c|}{ Rural } & \multicolumn{4}{|c|}{ Urban } \\
\hline & \multirow{2}{*}{$\begin{array}{c}\text { Mean } \\
\text { WEDR/1000 }\end{array}$} & \multicolumn{2}{|c|}{ Females $(19,774)$} & \multicolumn{2}{|c|}{ Males(21,441) } & \multicolumn{2}{|c|}{ Females $(3,691)$} & \multicolumn{2}{|c|}{ Males $(4,140)$} \\
\hline & & $\begin{array}{l}\text { Mothers } \\
\text { Born \% }\end{array}$ & $\begin{array}{c}\text { Entered } \\
\text { J. } \\
\text { HS \% }\end{array}$ & $\begin{array}{c}\text { Mothers } \\
\text { Born \% }\end{array}$ & $\begin{array}{c}\text { Entered } \\
\text { J. } \\
\text { HS \% }\end{array}$ & $\begin{array}{c}\text { Mothers } \\
\text { Born \% }\end{array}$ & $\begin{array}{c}\text { Entered } \\
\text { J. } \\
\text { HS \% }\end{array}$ & $\begin{array}{c}\text { Mothers } \\
\text { Born \% }\end{array}$ & $\begin{array}{c}\text { Entered } \\
\text { J. } \\
\text { HS \% }\end{array}$ \\
\hline 1954 & 1.01 & 3.48 & 70.1 & 3.61 & 74.6 & 2.95 & 95.4 & 3.26 & 91.9 \\
\hline 1955 & 0.48 & 4.31 & 67.9 & 4.66 & 72.2 & 2.90 & 94.3 & 3.77 & 91.7 \\
\hline 1956 & 0.06 & 5.12 & 70.7 & 5.54 & 71.4 & 4.06 & 93.3 & 4.37 & 94.5 \\
\hline 1957 & -0.46 & 6.07 & 69.8 & 6.17 & 74.0 & 5.58 & 93.2 & 6.64 & 91.2 \\
\hline 1958 & 0.27 & 6.23 & 68.4 & 6.46 & 74.2 & 6.77 & 91.6 & 6.47 & 94.4 \\
\hline 1959 & 3.10 & 5.37 & 69.0 & 5.45 & 74.8 & 7.40 & 94.9 & 6.62 & 92.0 \\
\hline 1960 & 9.26 & 6.54 & 69.7 & 6.75 & 72.5 & 9.16 & 94.7 & 9.52 & 94.7 \\
\hline 1961 & 6.77 & 6.92 & 67.7 & 6.77 & 72.7 & 8.91 & 91.8 & 8.67 & 93.3 \\
\hline 1962 & -0.29 & 13.49 & 70.5 & 13.52 & 74.7 & 15.98 & 94.1 & 15.34 & 92.9 \\
\hline 1963 & -1.66 & 15.99 & 72.0 & 15.52 & 75.5 & 17.04 & 92.2 & 16.76 & 91.6 \\
\hline 1964 & -0.65 & 11.47 & 68.8 & 11.03 & 70.8 & 9.35 & 91.6 & 9.90 & 91.7 \\
\hline 1965 & -1.26 & 9.27 & 66.7 & 8.75 & 68.3 & 6.39 & 88.1 & 6.06 & 87.3 \\
\hline 1966 & -2.51 & 5.70 & 62.6 & 5.76 & 64.2 & 3.49 & 84.5 & 2.61 & 84.2 \\
\hline $\begin{array}{r}\text { Total or } \\
\text { Mean }\end{array}$ & -1.24 & 100 & 69.2 & 100 & 72.6 & 100 & 92.5 & 100 & 92.2 \\
\hline
\end{tabular}

Notes:

1. WEDR is for rural male sample 
Table 1b Sample Statistics

\begin{tabular}{|c|c|c|c|c|c|c|c|c|c|}
\hline & & Of & $\mathrm{g}$ Ch & teris & se 1 & $\ln 2$ & & & \\
\hline Mother & & & Rural & & & & & & \\
\hline $\begin{array}{l}\text { S Birtn } \\
\text { Year }\end{array}$ & $\begin{array}{c}\text { Mean } \\
\text { WEDR/10 }\end{array}$ & $\begin{array}{l}\text { Fen } \\
(12,\end{array}$ & $\begin{array}{l}\text { ales } \\
80 \text { ) }\end{array}$ & Males( & $4,253)$ & Females & $(3,373)$ & Males & 3804) \\
\hline & & $\begin{array}{c}\text { Mother } \\
\text { s } \\
\text { Born } \\
\%\end{array}$ & $\begin{array}{c}\text { Entere } \\
\text { d } \\
\text { S. } \\
\text { HS \% }\end{array}$ & $\begin{array}{c}\text { Mother } \\
\text { s } \\
\text { Born } \\
\%\end{array}$ & $\begin{array}{c}\text { Entere } \\
\text { d } \\
\text { S. } \\
\text { HS \% }\end{array}$ & $\begin{array}{c}\text { Mother } \\
\text { s } \\
\text { Born } \\
\%\end{array}$ & $\begin{array}{c}\text { Entere } \\
\text { d } \\
\text { S. } \\
\text { HS \% }\end{array}$ & $\begin{array}{c}\text { Mother } \\
\text { s } \\
\text { Born } \\
\%\end{array}$ & $\begin{array}{c}\text { Entere } \\
\text { d } \\
\text { S. } \\
\text { HS \% }\end{array}$ \\
\hline 1954 & 1.40 & 7.84 & 14.2 & 7.79 & 17.5 & 7.56 & 79.2 & 7.52 & 73.6 \\
\hline 1955 & 0.81 & 9.49 & 13.5 & 9.89 & 17.0 & 10.52 & 82.3 & 10.36 & 78.7 \\
\hline 1956 & 0.16 & 10.25 & 15.4 & 10.59 & 19.9 & 13.25 & 77.1 & 12.88 & 74.9 \\
\hline 1957 & -0.43 & 11.67 & 16.2 & 12.38 & 20.5 & 16.99 & 78.2 & 16.64 & 77.7 \\
\hline 1958 & 0.18 & 11.81 & 16.1 & 11.42 & 18.9 & 15.48 & 77.1 & 16.11 & 73.2 \\
\hline 1959 & 2.75 & 9.24 & 17.4 & 8.98 & 19.8 & 10.91 & 75.9 & 10.75 & 69.3 \\
\hline 1960 & 8.46 & 9.42 & 15.8 & 8.97 & 18.1 & 8.89 & 70.2 & 9.36 & 63.6 \\
\hline 1961 & 7.28 & 6.88 & 14.2 & 6.84 & 18.9 & 4.18 & 66.2 & 4.50 & 56.8 \\
\hline 1962 & -0.38 & 10.04 & 13.9 & 10.13 & 15.8 & 6.34 & 62.8 & 6.02 & 59.4 \\
\hline 1963 & -1.72 & 7.66 & 9.5 & 7.30 & 13.4 & 3.47 & 54.3 & 3.34 & 59.2 \\
\hline 1964 & -0.68 & 3.46 & 7.7 & 3.42 & 12.5 & 1.39 & 45.7 & 1.63 & 43.9 \\
\hline 1965 & -0.97 & 1.55 & 8.5 & 1.67 & 8.9 & 0.71 & 39.1 & 0.71 & 34.8 \\
\hline 1966 & -2.12 & 0.70 & 4.9 & 0.62 & 9.1 & 0.3 & 40.0 & 0.18 & 42.9 \\
\hline $\begin{array}{r}\text { Total or } \\
\text { Mean }\end{array}$ & & 100 & 14.4 & 100 & 17.7 & 100 & 74.2 & 100 & 70.7 \\
\hline
\end{tabular}

1. WEDR is for rural male sample 
Table 2a

Dependent Variable Junior High School Entrance

Females Age 13-15 in 2000 Mothers born 1954-1966 (age 34-46 in 2000)

Youngest possible age of mother at birth of child 19 years; oldest possible 33 years

\begin{tabular}{|c|c|c|c|c|c|c|c|c|c|}
\hline \multirow{2}{*}{ Regressors } & \multicolumn{7}{|c|}{ Rural } & \multicolumn{2}{|c|}{ Urban } \\
\hline & Probit & Probit & Probit & Probit & Probit & Probit & 2S Probit & Probit & Probit \\
\hline WEDR Moth. In utero & $\begin{array}{r}-8.84 \\
(-1.78) \\
{[-3.03]} \\
\{-0.016\} \\
\end{array}$ & $\begin{array}{r}-7.68 \\
(-2.13) \\
{[-2.61]} \\
\{-0.014\} \\
\end{array}$ & & & $\begin{array}{r}-8.71 \\
(-4.54) \\
{[-2.89]} \\
\{--0.015\} \\
\end{array}$ & $\begin{array}{r}-9.00 \\
(-1.84) \\
{[-3.09]} \\
\{-0.017\} \\
\end{array}$ & $\begin{array}{r}-31.92 \\
(-1.96) \\
{[-13.38]} \\
\{-0.071\} \\
\end{array}$ & $\begin{array}{r}12.19 \\
(1.90) \\
{[1.26]} \\
\{0.007\} \\
\end{array}$ & $\begin{array}{r}8.98 \\
(1.33) \\
{[0.90]} \\
\{.0055\} \\
\end{array}$ \\
\hline WEDR Moth. Birth Year+1 & & & $\begin{array}{r}-5.70 \\
(-3.01) \\
{[-1.96]} \\
\{-0.010\} \\
\end{array}$ & & & & & & \\
\hline WEDR Moth. Birth Year+2 & & & & $\begin{array}{r}-6.18 \\
(-2.97) \\
{[-2.11]} \\
\{-0.012\} \\
\end{array}$ & & & & & \\
\hline WEDR0*WEDR2*1000 & & & & & $\begin{array}{r}-0.13 \\
(-1.09) \\
{[-0.045]} \\
\{--0.0019\} \\
\end{array}$ & & & & \\
\hline Mother Born in Different Province (Migrant) & & & & & & $\begin{array}{r}-0.29 \\
(-0.08) \\
\end{array}$ & & & $\begin{array}{r}-.072 \\
(-0.37) \\
\end{array}$ \\
\hline Migrant*WEDR Moth. Birth Year & & & & & & $\begin{array}{r}23.18 \\
(1.50) \\
\end{array}$ & & & $\begin{array}{r}225.8 \\
(2.66) \\
\end{array}$ \\
\hline Housetype 2 & & $\begin{array}{r}-0.19 \\
(-3.60) \\
\end{array}$ & & & & & & & \\
\hline Housetype 3 & & $\begin{array}{r}-0.46 \\
(-7.31) \\
\end{array}$ & & & & & & & \\
\hline Housetype 4 & & $\begin{array}{r}-0.42 \\
(-6.47)\end{array}$ & & & & & & & \\
\hline House Area & & $\begin{array}{r}0.0058 \\
(8.08)\end{array}$ & & & & & & & \\
\hline \# Offspring & & $\begin{array}{r}-0.15 \\
(-5.98)\end{array}$ & & & & & & & \\
\hline Const & $\begin{array}{r}0.19 \\
(2.85) \\
\end{array}$ & $\begin{array}{r}0.66 \\
(6.92) \\
\end{array}$ & $\begin{array}{r}0.18 \\
(2.82) \\
\end{array}$ & $\begin{array}{r}0.18 \\
(2.79) \\
\end{array}$ & $\begin{array}{r}0.19 \\
(2.83) \\
\end{array}$ & $\begin{array}{r}0.20 \\
(3.04) \\
\end{array}$ & $\begin{array}{r}0.32 \\
(2.38) \\
\end{array}$ & $\begin{array}{r}2.63 \\
(12.7) \\
\end{array}$ & $\begin{array}{r}2.61 \\
(12.11) \\
\end{array}$ \\
\hline R-sq. (pseudo R-sq probit) & 0.084 & 0.12 & 0.083 & 0.083 & 0.084 & 0.084 & $\mathrm{xxxx}$ & 0.13 & 0.14 \\
\hline $\mathrm{N}$ & 19,774 & 19,472 & 19,774 & 19,774 & 19,774 & 19,774 & 19,337 & 3,917 & 3,917 \\
\hline Wald test Prob>Chi sq & & & & & & & 0.15 & & \\
\hline Amemiya-Lee-Newey P-value & & & & & & & 0.06 & & \\
\hline
\end{tabular}




\section{Table 2b}

Dependent Variable Junior High School Entrance

Males Age 13-15 in 2000 Mothers born 1954-1966 (age 34-46 in 2000)

Youngest possible age of mother at birth of child 19 years; oldest possible 33 years

\begin{tabular}{|c|c|c|c|c|c|c|c|c|c|}
\hline \multirow[t]{2}{*}{ Regressors } & \multicolumn{7}{|c|}{ Rural } & \multicolumn{2}{|c|}{ Urban } \\
\hline & Probit & Probit & Probit & Probit & Probit & Probit & 2S Probit & Probit & Probit \\
\hline WEDR Moth. In utero & $\begin{array}{r}-9.28 \\
(-3.59) \\
{[-2.93]} \\
\{-0.016\} \\
\end{array}$ & $\begin{array}{r}-8.02 \\
(-2.66) \\
{[-2.49]} \\
\{-0.014\}\end{array}$ & & & $\begin{array}{r}-9.54 \\
(-6.38) \\
{[-3.02]} \\
\{-0.016\}\end{array}$ & $\begin{array}{r}-9.24 \\
(2.78) \\
{[-2.92} \\
\{-0.15\}]\end{array}$ & $\begin{array}{l}-36.75 \\
(-2.10) \\
{[-17.5]} \\
\{-.096\}\end{array}$ & $\begin{array}{r}5.57 \\
(0.74) \\
{[0.66]} \\
\{0.003\}\end{array}$ & $\begin{array}{r}4.92 \\
(0.61) \\
{[0.58]} \\
\{0.003\}\end{array}$ \\
\hline WEDR Moth. Birth Year+1 & & & $\begin{array}{r}-4.44 \\
(-1.43) \\
{[-1.40]} \\
\{-0.0075\}\end{array}$ & & & & & & \\
\hline WEDR Moth. Birth Year+2 & & & & $\begin{array}{r}4.28 \\
(1.91) \\
{[1.35]} \\
\{0.0076\} \\
\end{array}$ & & & & & \\
\hline WEDR0*WEDR2*1000 & & & & & $\begin{array}{r}0.54 \\
(4.39) \\
{[0.17]} \\
\{0.0073\}\end{array}$ & & & & \\
\hline Mother Born in Different Province (Migrant) & & & & & & $\begin{array}{r}-0.33 \\
(-2.95) \\
\end{array}$ & & & $\begin{array}{r}-0.02 \\
(-0.12) \\
\end{array}$ \\
\hline Migrant*WEDR Moth. Birth Year & & & & & & $\begin{array}{l}-14.9 \\
(-0.5)\end{array}$ & & & $\begin{array}{r}12.48 \\
(0.5)\end{array}$ \\
\hline Housetype 2 & & $\begin{array}{l}-0.194 \\
(-4.25)\end{array}$ & & & & & & & \\
\hline Housetype 3 & & $\begin{array}{l}-0.488 \\
(-7.42) \\
\end{array}$ & & & & & & & \\
\hline Housetype 4 & & $\begin{array}{l}-0.393 \\
(-4.93)\end{array}$ & & & & & & & \\
\hline House Area & & $\begin{array}{r}0.0036 \\
(4.63) \\
\end{array}$ & & & & & & & \\
\hline \# Offspring & & $\begin{array}{r}-0.180 \\
(-7.18)\end{array}$ & & & & & & & \\
\hline Const & $\begin{array}{r}0.42 \\
(6.32)\end{array}$ & $\begin{array}{r}1.78 \\
(12.94)\end{array}$ & $\begin{array}{r}0.41 \\
(6.33) \\
\end{array}$ & $\begin{array}{r}0.40 \\
(6.17) \\
\end{array}$ & $\begin{array}{r}0.42 \\
(6.34)\end{array}$ & $\begin{array}{r}0.43 \\
(6.41) \\
\end{array}$ & $\begin{array}{r}0.93 \\
(5.83)\end{array}$ & $\begin{array}{r}0.69 \\
(4.57)\end{array}$ & $\begin{array}{r}0.70 \\
(4.57) \\
\end{array}$ \\
\hline R-sq. (pseudo R-sq probit) & 0.11 & 0.14 & 0.11 & 0.11 & 0.11 & 0.11 & & 0.10 & 0.10 \\
\hline 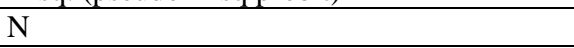 & 21,441 & 21,111 & 21,441 & 21,441 & 21,441 & 21,441 & 20,986 & 4,329 & 4,329 \\
\hline Wald test Prob $>$ Chi sq & & & & & & & 0.11 & & \\
\hline Amemiya-Lee-Newey P-value & & & & & & & 0.37 & & \\
\hline
\end{tabular}




\section{Table 2c}

Dependent Variable Senior High School Entrance

Females Age 16-18 in 2000 Mothers born 1954-1966 (age 34-46 in 2000)

Youngest possible age of mother at birth of child 16 years; oldest possible 30 years

\begin{tabular}{|c|c|c|c|c|c|c|c|c|}
\hline \multirow[t]{2}{*}{ Regressors } & & \multicolumn{5}{|c|}{ Rural } & \multicolumn{2}{|c|}{ Urban } \\
\hline & Probit & Probit & Probit & Probit & Probit & 2S Probit & Probit & Probit \\
\hline WEDR Moth. In utero & $\begin{array}{r}-3.79 \\
(-2.34) \\
{[-0.81]} \\
\{-0.0045\} \\
\end{array}$ & $\begin{array}{r}-2.92 \\
(-1.05) \\
{[-0.61]} \\
\{-0.0034 \\
\end{array}$ & & & $\begin{array}{r}-3.75 \\
(2.32) \\
{[-0.80]} \\
\{.00045\} \\
\end{array}$ & $\begin{array}{r}0.20 \\
(0.01) \\
{[0.53]} \\
\{0.0029\} \\
\end{array}$ & $\begin{array}{r}7.54 \\
(1.80) \\
{[2.34]} \\
\{0.014\} \\
\end{array}$ & $\begin{array}{r}8.76 \\
(1.67) \\
{[2.72} \\
\{0.016\} \\
\end{array}$ \\
\hline WEDR Moth. Birth Year+1 & & & $\begin{array}{r}-0.59 \\
(-0.13) \\
{[-0.13]} \\
\{-0.0008\}\end{array}$ & & & & & \\
\hline WEDR Moth. Birth Year+2 & & & & $\begin{array}{r}-4.81 \\
(-1.91) \\
{[1.04]} \\
\{-0.0064\} \\
\end{array}$ & & & & \\
\hline Mother Born in Different Province (Migrant) & & & & & $\begin{array}{r}0.12 \\
(0.92)\end{array}$ & & & $\begin{array}{r}-0.08 \\
(-0.59)\end{array}$ \\
\hline Migrant*WEDR Moth. Birth Year & & & & & $\begin{array}{r}-7.05 \\
(-0.38)\end{array}$ & & & $\begin{array}{r}--8.16 \\
(-0.42)\end{array}$ \\
\hline Housetype 2 & & $\begin{array}{r}-0.30 \\
(-3.70) \\
\end{array}$ & & & & & & \\
\hline Housetype 3 & & $\begin{array}{r}-0.56 \\
(-5.07) \\
\end{array}$ & & & & & & \\
\hline Housetype 4 & & $\begin{array}{r}-0.53 \\
(-5.97)\end{array}$ & & & & & & \\
\hline House Area & & $\begin{array}{r}0.0048 \\
(8.50) \\
\end{array}$ & & & & & & \\
\hline \# Offspring & & $\begin{array}{r}-0.027 \\
(-1.36)\end{array}$ & & & & & & \\
\hline Const & $\begin{array}{r}-0.34 \\
(-1.85) \\
\end{array}$ & $\begin{array}{r}-0.39 \\
(-2.81) \\
\end{array}$ & $\begin{array}{r}-0.33 \\
(-1.78) \\
\end{array}$ & $\begin{array}{r}-0.36 \\
(-1.85) \\
\end{array}$ & $\begin{array}{r}-0.35 \\
(-1.88) \\
\end{array}$ & $\begin{array}{r}-1.16 \\
(-5.00) \\
\end{array}$ & $\begin{array}{r}-0.36 \\
(-0.69) \\
\end{array}$ & $\begin{array}{r}-0.36 \\
(-0.52) \\
\end{array}$ \\
\hline R-sq. (pseudo R-sq probit) & 0.05 & 0.08 & 0.05 & 0.05 & 0.05 & & 0.08 & 0.08 \\
\hline $\mathrm{N}$ & 12,180 & 12,019 & 12,180 & 12,180 & 12,180 & 11,921 & 3,373 & 3,373 \\
\hline Wald test Prob $>$ Chi sq & & & & & & 0.89 & & \\
\hline Amemiya-Lee-Newey P-value & & & & & & 0.73 & & \\
\hline
\end{tabular}




\section{Table 2d}

Dependent Variable Senior High School Entrance

Males Age 16-18 in 2000 Mothers born 1954-1966 (age 34-46 in 2000)

Youngest possible age of mother at birth of child 16 years; oldest possible 30 years

\begin{tabular}{|c|c|c|c|c|c|c|c|c|}
\hline \multirow[t]{2}{*}{ Regressors } & & \multicolumn{5}{|c|}{ Rural } & \multicolumn{2}{|c|}{ Urban } \\
\hline & Probit & Probit & Probit & Probit & Probit & 2S Probit & Probit & Probit \\
\hline WEDR Moth. In utero & $\begin{array}{r}-3.66 \\
(4.03) \\
{[-0.91]} \\
\{-0.0051\}\end{array}$ & $\begin{array}{r}-3.83 \\
(-0.93) \\
{[-0.93)} \\
\{-0.0052\}\end{array}$ & & & $\begin{array}{r}-3.62 \\
(-4.18 \\
{[-0.90]} \\
\{-0.0051\}\end{array}$ & $\begin{array}{r}-5.59 \\
(-0.28) \\
{[-1.32]} \\
\{-0.0074\}\end{array}$ & $\begin{array}{r}6.38 \\
(1.28) \\
{[2.15]} \\
\{0.010\}\end{array}$ & $\begin{array}{r}6.84 \\
(1.33) \\
{[2.30]} \\
\{0.11\}\end{array}$ \\
\hline WEDR Moth. Birth Year+1 & & & $\begin{array}{r}-1.79 \\
(-0.48) \\
{[-0.44]} \\
\{-0.0002\}\end{array}$ & & & & & \\
\hline WEDR Moth. Birth Year+2 & & & & $\begin{array}{r}-3.65 \\
(-1.01) \\
{[-0.92]} \\
\{-.0052\}\end{array}$ & & & & \\
\hline Mother Born in Different Province (Migrant) & & & & & $\begin{array}{c}0.009 \\
(0.06)\end{array}$ & & & $\begin{array}{r}-0.10 \\
(-0.84)\end{array}$ \\
\hline Migrant*WEDR Moth. Birth Year & & & & & $\begin{array}{r}-2.12 \\
(-0.12)\end{array}$ & & & $\begin{array}{r}-9.63 \\
(-0.92)\end{array}$ \\
\hline Housetype 2 & & $\begin{array}{r}-0.12 \\
(-1.68)\end{array}$ & & & & & & \\
\hline Housetype 3 & & $\begin{array}{r}-0.37 \\
(-3.43) \\
\end{array}$ & & & & & & \\
\hline Housetype 4 & & $\begin{array}{r}-0.29 \\
(-3.87)\end{array}$ & & & & & & \\
\hline House Area & & $\begin{array}{r}0.0031 \\
(7.97)\end{array}$ & & & & & & \\
\hline \# Offspring & & $\begin{array}{c}-0.042 \\
(-1.72)\end{array}$ & & & & & & \\
\hline Const & $\begin{array}{r}-0.11 \\
(-0.88) \\
\end{array}$ & $\begin{array}{r}-0.0003 \\
(-0.00)\end{array}$ & $\begin{array}{r}-0.10 \\
(-0.87) \\
\end{array}$ & $\begin{array}{r}-0.11 \\
(-0.93) \\
\end{array}$ & $\begin{array}{r}-0.11 \\
(-0.95) \\
\end{array}$ & $\begin{array}{r}-1.55 \\
(-6.10) \\
\end{array}$ & $\begin{array}{r}-0.34 \\
(-0.79) \\
\end{array}$ & $\begin{array}{r}-0.27 \\
((-1.11) \\
\end{array}$ \\
\hline R-sq. (pseudo R-sq probit) & 0.06 & 0.07 & 0.06 & 0.06 & 0.06 & & 0.07 & 0.07 \\
\hline $\mathrm{N}$ & 14,253 & 14,038 & 14,253 & 14,253 & 14,253 & 13,940 & 3,804 & 3,804 \\
\hline Wald test Prob $>$ Chi sq & & & & & & 0.93 & & \\
\hline Amemiya-Lee-Newey P-value & & & & & & 0.49 & & \\
\hline
\end{tabular}


Notes to all tables.

i. Marginal probability at mean in brackets. Product of marginal probability at mean and one standard deviation of regressor in braces. T- or Zstatistics in parentheses.

ii.There are $69.2 \%$ of the sample of rural females and $92.4 \%$ of urban females age $13-15$ who have at least one year of junior high school.

iv. All estimates include dummy variables for mother's birth province, mother's birth year, and offspring age.

v. All 2S Probit are based on first-stage regressions using five weather dummies as instrumental variables ;and which include dummy variables for mother's birth province, mother's birth year, and child's birth date.. 
Table 3 First Step Regressions for WEDR/1000 in Mother’s Birth Year, Rural Offspring Age 13-15 in 2000

\begin{tabular}{|l|r|r|r|}
\hline & Females & \multicolumn{2}{|c|}{ Males } \\
\hline Weather Good & 1.31 & 1.23 & 1.22 \\
& $(10.16$ & $(9.85)$ & $(9.68)$ \\
\hline Weather Average & 1.78 & 1.79 & 1.78 \\
& $(13.57)$ & $(14.07)$ & $(13.97)$ \\
\hline Weather Bad & 2.41 & 2.28 & 2.27 \\
& $(18.35)$ & $(18.27)$ & $(18.13)$ \\
\hline Weather Very Bad & 2.33 & 2.10 & 2.12 \\
& $(16.20)$ & $(15.13)$ & $(15.20)$ \\
\hline House Type XXX & & & 0.22 \\
& & & $(1.88)$ \\
\hline House Type YYY & & & 0.04 \\
& & & $(0.22)$ \\
\hline House Type ZZZ & & & 0.37 \\
& & & $(2.65)$ \\
\hline House Area M ${ }^{2} / 100$ & & & -0.14 \\
& & & $(-1.65)$ \\
\hline Number of Children & & & 0.09 \\
& & & $(1.92)$ \\
\hline Constant & -1.96 & -0.40 & -0.001 \\
& $(-4.39)$ & $(-0.76)$ & $(-1.88)$ \\
\hline Adj R-sq. & 0.41 & 0.40 & 0.40 \\
\hline
\end{tabular}

Notes:

1. Sample size is 19,337 for males and 20,896 for females

2. Omitted dummy variables are Weather Very Good and House Type XXXX

3. Each regression includes dummy variables for mother's birth province and mother's birth year. 